\title{
LIFE-THREATENING ANEMIA DIAGNOSIS DUE TO MYOMA UTERI IN THE EMERGENCY DEPARTMENT: A CASE REPORT
}

\author{
Abdullah ALGIN*, Ismail TAYFUR**, Mustafa Ahmet AFACAN**, Şahin ÇOLAK**, Mehmet SARIAYDIN***, Hüseyin Avni FINDIKLI*** \\ Hakan AYDIN*** \\ * Department of Emergency Medicine, Adıyaman University Training and Research Hospital Adıyaman, Turkey \\ ** Department of Emergency Medicine, SBU Haydarpasa Numune Training and Research Hospital, Istanbul, Turkey \\ *** Department of Internal Medicine, Adıyaman University Training and Research Hospital Adıyaman, Turkey
}

\begin{abstract}
Uterine myoma is a benign tumor of the uterus and clinically apparent in up to $25 \%$ of reproductive-age women. Emerged silent uterine bleedings are commonly seen with myoma. Although therapies via surgical and radiological way are frequently used for the management of the tumor, medical therapies are considered as initial treatment. When the anemia diagnosis cannot be made and cannot properly treated; it is not only reduces the patient's life quality, but also threatens the patient's life.

In this case report; we aim to present a rare case of the lowest hemoglobin level in the literature by a value of $1.2 \mathrm{~g} / \mathrm{dL}$ hemoglobin due to anemia resulted myoma uteri patient admitted to the emergency department by walk.

All case with severe anemia at a level lower than $4 \mathrm{~g} / \mathrm{dL}$ is rarely seen in the hospital emergency. Sometimes there are complaints of dysphagia, fragile nails, relative impotence, fatigue and cramps in the calves on climbing stairs, which are disproportionate to their anemia. In contrast to all recent reports, our case had the lowest hemoglobin levels reported ever, without a noisy clinical table indicating anemia.
\end{abstract}

Keywords: Anemia, Myoma, Hemorrhage

\section{Introduction}

Uterine myoma is a benign tumor of the uterus and clinically apparent in up to $25 \%$ of reproductive-age women . The silent uterine bleeding usually develops secondary to myoma $(2,3)$. Bleeding, anemia, fatigue and orthostatic hypotension are common events in emergency department. Severe anemia at a level $<4 \mathrm{~g} / \mathrm{dL}$ is rarely seen in the hospital enviroment. Two cases with such low hemoglobin levels have been published before. The first case hemoglobin level of 1.8 $\mathrm{g} / \mathrm{dL}$ have been reported from a patient standing by Imaizumi et al, and this was due to chronic urinary bleeding. Other anemia was reported by Schmitt et al. as secondary to colon cancer with a hemoglobin level of $1.8 \mathrm{~g} / \mathrm{dL}$. . Our case with a hemoglobin value of 1.2 is the lowest hemoglobin value in the literature.

\section{Case Report}

A 35-year-old previously healthy woman presented to the emergency department with the orientation of the polyclinic of obstetrics and gynecology. The complaint bringing the patient to the obstetrics and gynecology was mild tiredness and occasional vaginal bleeding. The diameter of the myoma had been measured as $4.2 \mathrm{~cm}$ in the polyclinic by Ultrasonography. The patient's heart rate was between 95 to 105 beats per minute, and his blood pressure was $115 / 85 \mathrm{mmHg}$ when supine but $90 / 40 \mathrm{~mm} \mathrm{Hg}$ upon standing. There was a generalized abdominal tenderness. The rhythms of the electrocardiogram were normal.

The patient had no history of hematopoietic disorders. She explained no history of hepatitis, intravenous drug use, prosthetic valves, or hemoptysis. Although the patient's fatigue and thyroid function tests were normal, there were complaints of shedding hair for 1 month. We did not define any feature other than non-irritating intermittent bleeding with not exceeding the size of a teaspoon. Based on a "diluted" sample, the initial laboratory evaluation was complicated by standard laboratory protocols rejecting the patient's complete blood count due to machine failure. After two rejected attempts, the emergency physician was asked to report the results, and then in the third specimen, a severe anemia with hemoglobin level of $1.2 \mathrm{~g} / \mathrm{dL}$ was seen (Table-1). Hepatitis marker was negative. Ferritin, iron 
was low. Iron binding capacity high.Peripheral blood smear contained hemolysis-related changes. Fecal occult blood test is negative.

The patient was given two units of erythrocyte suspension with appropriate cross-match blood. Hemoglobin increased to $3.93 \mathrm{~g} / \mathrm{dL}$ and hematocrit reached $15.4 \%$ after erythrocyte suspension was administered. The treatment was completed on the withdrawal of hemoglobin to normal levels, after making sure that your cancer screening tests are negative. She discharged 3 weeks after the admission and being followed by gynecological diseases.

\begin{tabular}{|l|c|c|}
\hline $\begin{array}{l}\text { TABLE 1. All hematological Parameters } \\
\text { range }\end{array}$ & were given with reference \\
\hline Hemotological Parameters & Value & Reference range \\
\hline Hemoglobin (g/dL) & 1,2 & $14-18$ \\
\hline Hematocrit (\%) & 7,7 & $42-52$ \\
\hline Red Blood Cells (u/L) & 1,25 & $4-6,13$ \\
\hline White Blood Cells (u/L) & 7,23 & $4,3-10,3$ \\
\hline Mean corpuscular volume (fL) & 60 & $80-97$ \\
\hline Mean corpuscular hemoglobin (pg) & 9,3 & $25-33,3$ \\
\hline $\begin{array}{l}\text { Mean corpuscular hemoglobin } \\
\text { concentration (g/dL) }\end{array}$ & 15,8 & $30-35$ \\
\hline Total iron binding capacity ( $\mu$ g/dL) & 499 & $241-421$ \\
\hline Transferrin saturation (\%) & 0,1 & $18 \%-48 \%$ \\
\hline Transferrin (mg/dL) & 249 & $180-344$ \\
\hline Blood Iron ( $\mu$ g/dL) & 17 & $30-162$ \\
\hline Haptoglobin (mg/dL) & 193 & $62-197$ \\
\hline Folat (pg/mL) & 11 & $2,5-20$ \\
\hline Vitamin B12 (nmol/L) & $180-914$ \\
\hline
\end{tabular}

\section{Discussion}

Case with severe anemia at a level lower than $4 \mathrm{~g} / \mathrm{dL}$ is rarely seen in the hospital emergency. However, those indicate clinical symptoms, when they reached the emergency department. Sometimes there are complaints of dysphagia, fragile nails, relative impotence, fatigue and cramps in the calves on climbing stairs, which are disproportionate to their anemia. In contrast, our case had no noisy table indicating severe anemia. There were only complaints of shedding hair for 1 month, with no history of hepatitis, prosthetic valves, intravenous drug use, or hemoptysis.

In literature knowledge, we encountered to two cases of low hemoglobin levels, which was not low as our case. Imaizumi et al has been reported a patient with a hemoglobin level of $1.8 \mathrm{~g} / \mathrm{dL}$ due to chronic urinary bleeding. And another anemia was reported by Schmitt et al, as emerged secondary to colon cancer with 1.8 $\mathrm{g} / \mathrm{dL}$. The most common source of blood loss leading to such severe anemia is the gastrointestinal system. There was no report for myoma uteri at this lowest level. The current patient adds to recent reports of patient survival with a hemoglobin level of $<2 \mathrm{~g} / \mathrm{dL}$, at the lowest level in the literature .

\section{References}

1. Orlandi $M$, Inauen W. [Chronic gastrointestinal bleeding]. Therapeutische Umschau Revue therapeutique. 2006;63(5):327-332.

2. Kurt H, Demirkiran D. Changing of Hemoglobin A1c Affects Mean Platelet Volume in Type-2 Diabetes Mellitus. Ulutas Med J. 2016;2(1):27-35.

3. Padmakumar R, Pai M, Farish S, Rajeev J, Sanjeev T, Sreevalsan TV, et al. Successful bowel surgery at hemoglobin $2 \mathrm{~g} / \mathrm{dL}$ without blood transfusion. World journal of gastrointestinal surgery. 2013;5(8):252255.

4. Rockey DC, Hafemeister AC, Reisch JS. Acute on chronic gastrointestinal bleeding: a unique clinical entity. Journal of investigative medicine : the official publication of the American Federation for Clinical Research. 2017;65(5):892-898.

5. Imaizumi T, Yagi E, Ushijima K, Suzuki K, Terasaki H. A patient with a preoperative hemoglobin concentration of 1.8 g.dl1: how was the lifethreatening anemia tolerated without any intensive care? Journal of anesthesia. 1999;13(2):125-126.

6. Schmitt RE, Buckley CJ. Extreme anemia (hemoglobin $1.8 \mathrm{~g} / \mathrm{dL}$ ) secondary to colon cancer. Proceedings (Baylor University Medical Center). 2016;29(4):393-4.

7. Zollinger A, Hager $P$, Singer T, Friedl HP, Pasch T, Spahn DR. Extreme hemodilution due to massive blood loss in tumor surgery. Anesthesiology. 1997;87(4):985-987. 